\title{
A quantitative ring recovery analysis of migration in European Water Rails Rallus aquaticus
}

\author{
Kristin Lugg ${ }^{1}$, Vidar Bakken² \& Terje Lislevand ${ }^{3 *}$ \\ ${ }^{1}$ Department of Biology, University of Bergen, Bergen, Norway \\ ${ }^{2}$ ARC Arctic Research and Consulting DA, Ombustvedtveien 20, 1592 Våler \\ ${ }^{3}$ Department of Natural History, University Museum of Bergen, University of Bergen, Bergen, Norway \\ *Correspondence: terje.lislevand@uib.no
}

\begin{abstract}
The Water Rail Rallus aquaticus is generally regarded as a facultative migrant in which migration patterns vary geographically. However, quantitative analyses of migration directions and how migration distances vary across Europe are hitherto lacking. We analysed recoveries of Water Rails ringed in Europe and tested for a general migration direction in this material. From previous literature descriptions we predicted birds to migrate farther the longer north and east they breed. More than half of the birds included in the data set were ringed in Germany (48\%) and Hungary (12\%) and most winter recoveries came from SW coastal Europe. We found that the migratory direction in autumn was strongly oriented towards SW with no effect of latitude or longitude of the breeding site. There were no differences in migration direction between old $(2 \mathrm{Y}+)$ and young $(1 \mathrm{Y})$ birds, or between males and females, although sample sizes were admittedly small in the latter comparison. As predicted, migration distances were positively correlated with both latitude and longitude of breeding sites. We encourage more trapping and ringing of Water Rails breeding and wintering across Europe in order to improve the ring recovery data. The use of modern tracking devices like light-level geolocators also has a high potential of improving our understanding of migratory ecology in this secretive species.
\end{abstract}

Keywords: migration, rails, ringing, ring recoveries

\section{INTRODUCTION}

Bird migration is often divided into two main classes (Terrill \& Able 1988, Alerstam 1990, Berthold 2001, Newton 2008): 1) facultative migration where movements are typically irregularly induced by exogenous factors (e.g. food availability and climate), and 2) obligate migration which is controlled by endogenous factors resulting in a regular annual movement between the breeding and non-breeding sites. Although migration in many species is readily classified according to this broad categorisation, some species show a considerable variation in migratory behaviour among populations. One way of improving our understanding about such variation is through the analysis of ring recoveries.

In the Water Rail Rallus aquaticus migration patterns are known to differ among European populations (Flegg \& Glue 1973, Cramp \& Simmons 1980, De Kroon 1984, Taylor \& van Perlo 1998). Winter occurrence in a specific area may vary considerably according to climatic conditions, the species being more numerous in mild seasons (Flegg \& Glue 1973, Lislevand \& Kjøstvedt 2005). According to Cramp and Simmons (1980) birds from the Atlantic and Mediterranean coasts are mainly sedentary, populations east and north of these areas are to some degree migratory and birds breeding east of approx. 13 degrees longitude are most likely all migratory. The species probably avoids areas with long periods of cold in winter, typically areas east of the $0^{\circ}$ isotherm for January (De Kroon 1984). Although several national analyses of Water Rail ring recoveries exist (e.g. Bakken et al. 2003, Fransson et al. 2008, Saurola et al. 2013), as well as a few continentwide studies (Flegg \& Glue 1973, De Kroon 1984), these have been largely qualitative. Studies on the species' migration behaviour are therefore to some extent inconclusive. For instance, migration is reported to go along axes in both the east-west and north-south directions in western parts of Europe (De Kroon 1984) but as far as we are aware no analyses have yet statistically evaluated the geographical variation in migration directions and migration distances.

Here we studied migratory patterns in European Water Rails by using ring recovery data obtained from The European Union for Bird Ringing (EURING) databank. Compared with previous studies on this topic we used a more quantitative approach and based our analyses on a larger data set than previous reports. We tested 1) for a general migration direction in the material and 2) if migration directions were related to latitude and longitude of the breeding sites. If migration distances differed between populations, we predicted that birds breeding further north and east should migrate farther than more southern and western breeding populations which presumably are located closer to the non-breeding areas. 
Table 1. An overview of the numbers and relative percentages of ring recoveries of European Water Rails. Countries/regions represent the ringing location. Only time periods from which recoveries exist are given (source: EURING).

\begin{tabular}{|c|c|c|c|}
\hline Country/region & Period & Recoveries (n) & $\%$ \\
\hline The North Sea .............. & 1958-1971 & 1 & 0.1 \\
\hline Austria.............................. & 1954-2002 & 14 & 1.5 \\
\hline Belgium............................. & 1955-2003 & 11 & 1.2 \\
\hline Channel Islands............ & 1951-1988 & 7 & 0.8 \\
\hline Czech Republic ............ & 1958-2004 & 58 & 6.3 \\
\hline Germany............................... & 1929-2007 & 435 & 47.6 \\
\hline Denmark............................ & 1929-1999 & 15 & 1.6 \\
\hline Spain ........................... & 1964-2008 & 29 & 3.2 \\
\hline France................................ & $1935-2005$ & 3 & 0.3 \\
\hline United Kingdom........... & 1937-2009 & 69 & 7.5 \\
\hline Switzerland ................. & 1928-2000 & 41 & 4.5 \\
\hline Hungary............................. & 1978-2006 & 109 & 11.9 \\
\hline Lithuania ............................ & 1999 & 1 & 0.1 \\
\hline The Netherlands ........... & 1934-2004 & 75 & 8.2 \\
\hline Norway .............................. & 1970-2001 & 3 & 0.3 \\
\hline Poland ............................... & 1967-2006 & 23 & 2.5 \\
\hline Finland ……...................... & 1954-1984 & 4 & 0.4 \\
\hline Sweden ............................... & 1960-1992 & 15 & 1.6 \\
\hline Republic of Serbia....... & 1932 & 1 & 0.1 \\
\hline Total & 1928-2009 & 914 & \\
\hline
\end{tabular}

\section{METHODS}

The EURING databank provides a useful tool for continental-scale studies of ringed birds, although data submission practices have differed somewhat through the years between different ringing schemes (du Feu et al. 2016). Consequently, the databank may not always be entirely up-to-date with regard to the number of ring recoveries included. We obtained the data set analysed here from EURING in 2009, meaning that also ring recoveries of Water Rails from the last few years are lacking. Nevertheless, our data set $(n=914)$ represents a considerable increase in the number of ring recoveries compared with previous studies (De Kroon 1982,$1984 ; \mathrm{n}=243$ ) and there is no reason to believe that the data points have been non-randomly selected in any ways. Consequently, our data set should be well suitable for quantitative analyses of migration direction and migration distances. We still emphasize that the aim of this paper is not to present the most complete overview of ring recoveries in Water Rails.

Water Rail ring recoveries spanned the period 1928-2009, a total of 81 years (Figure 1). Before analysis we removed data points where 1) date of ringing or recovery had an accuracy of less than two weeks; 2) accuracy of the given position was less than within a $20 \mathrm{~km}$ radius and 3) individuals were reported within seven days from ringing on the same locality. This reduced the data set by 240 data points, resulting in a total of 1045 ring recoveries from 914 individuals (99 individuals with 2-6 recoveries) in 19 countries or regions (Table 1). In analyses we used loxodrome distances and migration directions between ringing sites and recovery sites (Imboden \& Imboden 1972), as given in the EURING data bank.

Recoveries of birds ringed from 1 May to 31 July were assumed to be in their breeding areas, whereas birds recovered from 1 November throughout February were assumed to be in their winter quarters (Glutz von Blotzheim 1973, Cramp \& Simmons 1980, De Kroon 1984, Taylor 1996, Taylor \& van Perlo 1998). In analyses of migration distances, we used ring recoveries of birds marked in summer and recovered in any of the following winters, or birds ringed in winter and recovered in any of the following breeding seasons. In the current material few birds $(\mathrm{n}=7)$ were ringed in summer and recovered at the same site and in the same season in a subsequent year. However, most of these recoveries (5/7) were located within a radius of $10 \mathrm{~km}$ from the ringing site, thus indicating that the species shows a fairly high degree of philopatry.

To test for consistency in migratory directions we 


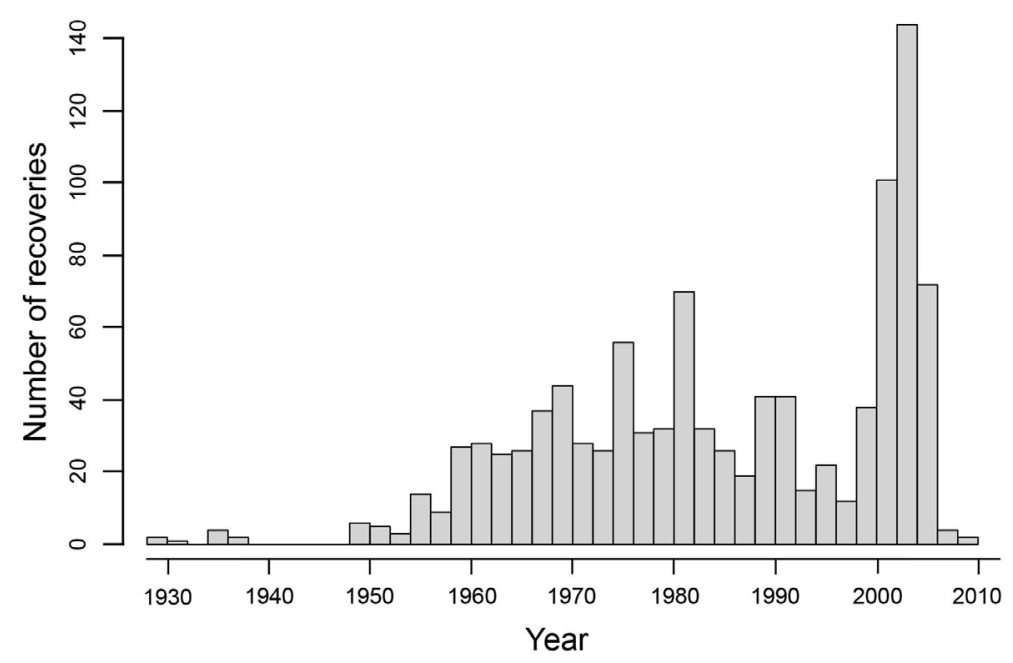

Figure 1. Temporal distribution of recoveries of Water Rails ringed in Europe. Each bar represents two years.

used information from individuals ringed in summer or during autumn migration (May - October) and recovered in August - December in the same year or January - February in the following year. Individuals moving $<100 \mathrm{~km}$ are excluded to reduce the risk of including more local and random movements different from real migration. Information about sex and age was available only for few individuals, thus restricting the possibilities of testing for differences related to these factors in migration distances and directions. With regard to age we separated between individuals ringed as young or in their first calendar year (1Y) and individuals ringed in their second calendar year or later $(2 \mathrm{Y}+)$.

Analyses were carried out using the software $\mathrm{R}$ (Version 2.9.0; R Development Core Team 2013). Recoveries are presented on Mercator projection maps where loxodromic distances are illustrated as straight lines. To investigate if autumn migration distances were related to the location of breeding areas we used a multiple regression with migration distance (in $\mathrm{km}$ ) as dependent variable against longitude and latitude of breeding site as independent variables. Starting with the full model (including the interaction term), variables without any significant explanatory value were removed from the full model in a stepwise manner.

To analyse migration directions, we used the circular package in R (Lund \& Agostinelli 2007). The circular distribution of directions makes it necessary to use circular statistics when testing for special trends in such data (Batschelet 1981). Migration directions are characterized by a vector with length $r$ and a direction $a$ (in degrees). The mean value of $r$ indicates the relative spread in the data set and varies between 0 (maximum spread) and 1 (no spread). To check the possibility that populations differ in migration directions we first tested if directions were related to the position of the breeding site (latitude and longitude) by using a multiple circular- linear regression. We also tested if migration direction differed between sexes or age categories (1Y vs. 2Y+, see above), using Welch t-tests. We tested for deviation from a random distribution of the migration directions by using the Rayleigh test (Batschelet 1981). Migration directions followed a von Mises distribution (Watson's test: $p=0.07$ ) but were not regarded as normally distributed (Shapiro-Wilks test: $p=0.056$ ). Hence, we report medians and quartiles as descriptive statistics for this variable. All tests are two-tailed and $\alpha=0.05$.

\section{RESULTS}

Since the first reported recovery of a ringed Water Rail in 1928 the annual numbers were low until around 1960, after which the number of ring recoveries increased slightly and remained fairly stable for a long period. During the last decade from which we have data there were a few years showing much higher numbers than the previous average (Figure 1). Of all recovered birds $(\mathrm{n}=914)$, most were ringed in Germany $(47.6 \%)$ and Hungary $(11.9 \%)$, while no other countries contributed with more than $10 \%$ of the total (Table 1). Also, a high proportion of ring recoveries came from Germany and Hungary, but with many also from France (18\%) where a low number of recovered birds were ringed (Table 1). About $31 \%$ of the 914 birds were reported as dead (n $=280)$. Of these, $66 \%(\mathrm{n}=186)$ were shot, $15.4 \%(\mathrm{n}=$ 43) were killed by predators (including domestic cats), $9.6 \%(\mathrm{n}=27)$ died from collisions with man-made structures and cars, $4.3 \%(\mathrm{n}=12)$ were found dead under natural circumstances, and the remaining $4.3 \%$ $(n=12)$ died from other causes.

The distributions of ring recoveries of birds reported in autumn and winter are shown in Figure $2 \mathrm{a}$ and $2 \mathrm{~b}$, respectively. Using these data in a circularlinear multiple regression with direction as dependent 

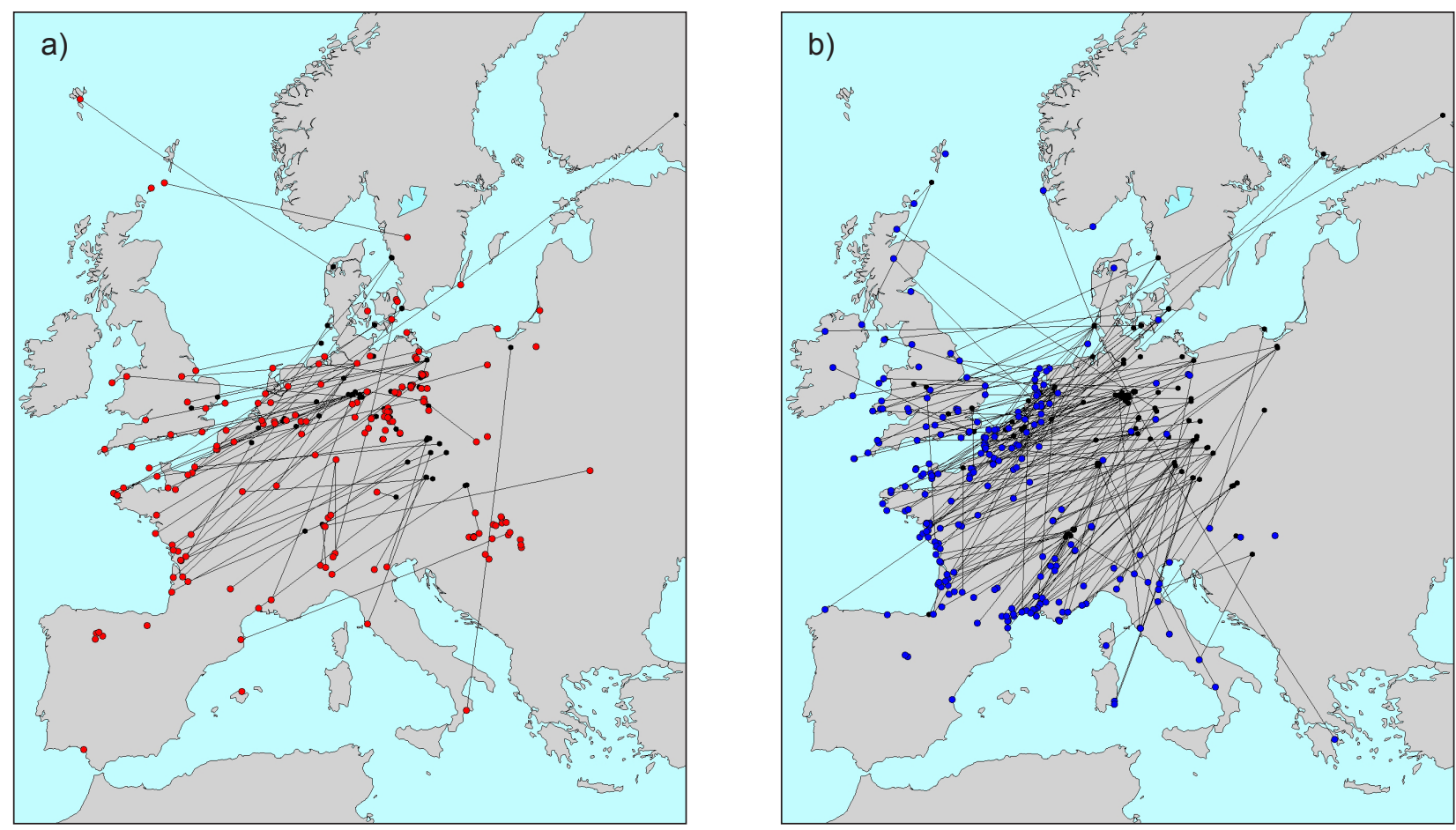

Figure 2. Distribution of ring recoveries in European Water Rails during autumn (a) and winter (b). Recovery sites are shown with red and blue dots, respectively.

variable we found no significant effect of longitude or latitude (longitude: $\mathrm{p}=0.75$; latitude, $\mathrm{p}=0.065$ ). Hence, directions were treated collectively to test for any particular trend in the material. Although migration directions varied extensively between $121^{\circ}$ and $340^{\circ}$, the total material showed a significant skew in a southwesterly direction $\left(\right.$ mean $=230^{\circ} \pm 4^{\circ} \mathrm{SD}, \mathrm{r}=0.88, \mathrm{p}<$ $0.001, \mathrm{n}=152$, Figure 3 ). In a restricted sample only including birds where sex was known we found no sex-related differences in migration direction (mean directions $=223^{\circ}[\mathrm{n}=7]$ and $225^{\circ}[\mathrm{n}=10]$ in females and males, respectively: $\mathrm{t}_{14.9}=0.19, \mathrm{p}=0.85$ ). Similarly, there were no differences between age groups (mean directions $=230^{\circ}$ in both $2 \mathrm{Y}+$ and $1 \mathrm{Y}$ birds $[\mathrm{n}=22$ and 108, respectively]; $\mathrm{t}_{31.8}=0.04, \mathrm{p}=0.97$ ).

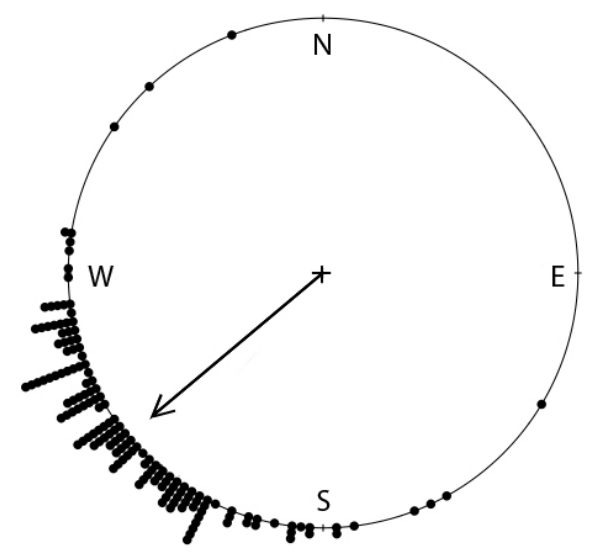

Figure 3. Migration directions for Water Rails in Europe ( $\mathrm{n}=$ 152). Mean direction $=230^{\circ} \pm 4(\mathrm{SD})$. Vector length: $\mathrm{r}=0.88$.
Most winter recoveries were located in coastal regions of central Western Europe (Figure 2b). We analysed the variation in migration distances and how these were related to longitudes and latitudes of presumed breeding localities by restricting the data set to recoveries of birds ringed between 1 May and 31 July and recovered from 1 November through February. Estimates of migration distance varied from $0 \mathrm{~km}$ to a maximum of $1805 \mathrm{~km}$ (median $=999 \mathrm{~km}$, quartiles $=593 \mathrm{~km}$ and $1168 \mathrm{~km}, \mathrm{n}=33$ ). A multiple linear regression showed that migration distance was positively related to both longitude and latitude of the presumed breeding sites where birds were ringed (longitude: $\mathrm{F}_{1,31}=24.29, \mathrm{p}<0.0001$; latitude: $\mathrm{F}_{1,31}=$ 9.53, $\mathrm{p}<0.005 ; \mathrm{r}^{2}=0.49 ;$ Figure 4).

\section{DISCUSSION}

In addition to providing insight into a bird species' basic biology, detailed information about the annual schedules of birds is imperative for the conservation of bird populations (Baillie 2001, Bowlin et al. 2010, Faaborg et al. 2010). Such information is still largely lacking in many species. Our quantitative analyses of ring recoveries in European Water Rails considerably increase our knowledge about movements in this species. We found that winter-time ring recoveries were predominantly located in south-western Europe, with only very few exceptions east of $13^{\circ}$ longitude as described by Cramp and Simmons (1980). This 
also corroborates the findings in previous ring recovery analyses (De Kroon 1982, 1984). However, conclusions about the main wintering areas of the species would rest on the assumption that the data used are representative for Water Rails throughout the WestEuropean breeding area, and that ringed birds do not behave differently from other birds (Clark et al. 2009). The Water Rail data may violate the former of these prerequisites since more than half the recovered birds had been ringed in Germany and Hungary, and few or no ring recoveries were available from birds breeding in countries located in more northern and eastern parts of Europe, or in North Africa. For instance, not a single Water Rail ringed in Norway has hitherto been recovered away from the ringing locality, and only four birds ringed abroad have been recovered in the country (Mork 1994, Norwegian Ring Recoveries Atlas 2017). Also, the probability that a ringed bird will be reported often varies both in time and space (Perdeck 1977, Bairlein 2001, Thorup \& Conn 2009) and it is hard to control for such possible biases in the data. It is further possible that our definitions of breeding, migration and non-breeding periods might have led to incorrect classification of some ring recoveries. For instance, some birds may start migrating already in July (Cramp $\&$ Simmons 1980) when we have assumed they are still on or near the breeding site. Similarly, some Water Rails have been found to move substantial distances as late as December (e.g. Bakken et al. 2003) when we assumed they were at the non-breeding site. Nevertheless, we believe that such instances of misclassification should be relatively few compared with those which are classified correctly.

Autumn migration of Water Rails showed a marked south-westerly direction in Europe but there were no relationships with latitude or longitude in this respect. Admittedly, however, the data set is restricted both in size and in sampling regions, perhaps making it unlikely that we would be able to demonstrate such directional differences. In addition, ring recoveries represent only "snapshots" of individual birds' spatial movements and do not provide any options for recording details of individual stopover use and migratory routes. It has for instance been suggested that adult Water Rails stop over en route to the wintering locations in order to carry out a post-nuptial moult (Cramp \& Simmons 1980). In a species like the Water Rail with a highly secretive behaviour and which is hard to monitor throughout the year, the use of modern bio-tracking techniques such as solar geolocators should have a great potential to provide novel insight into both this and other parts of the species' movement ecology.

Migration distances of Water Rails showed a considerable geographical variation within Europe. Birds breeding farther towards east and north migrated greater distances than birds from more southern and western locations. Presumably, this helps them to avoid
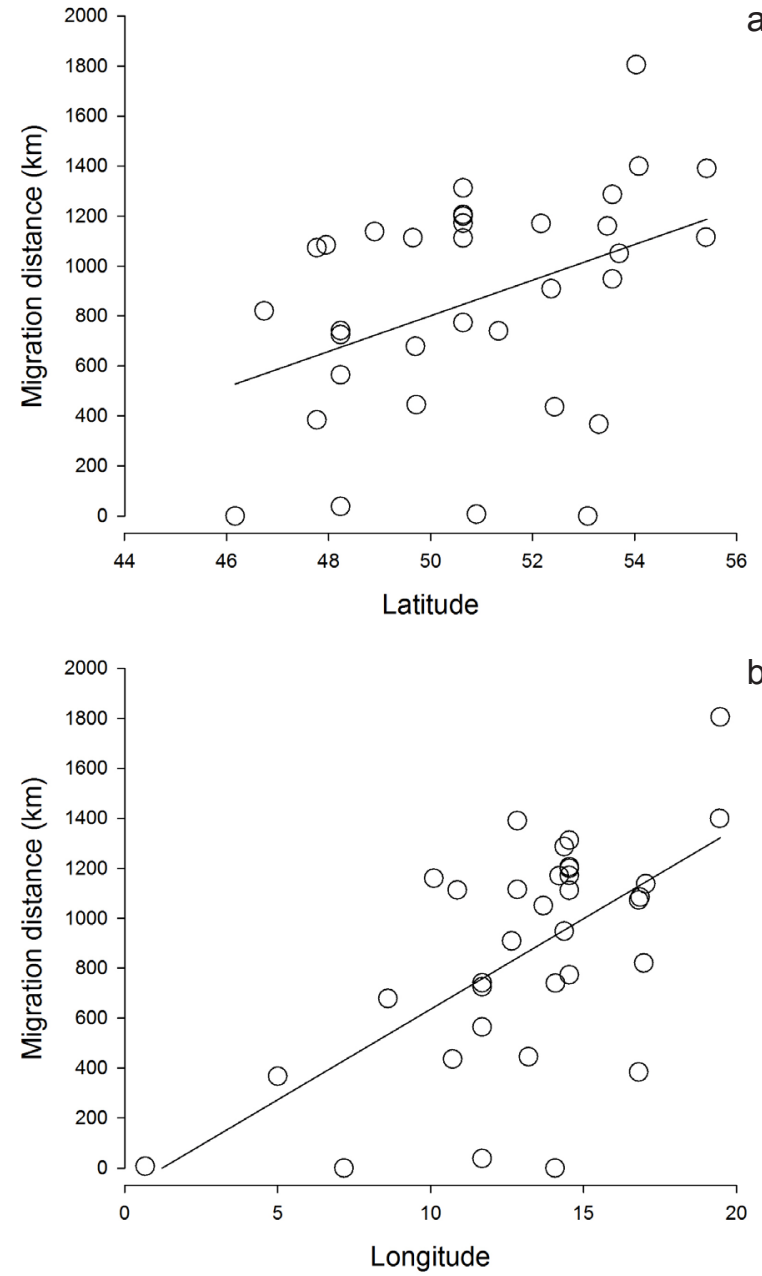

Figure 4. Migration distance of European Water Rails in relation to latitude (a) and longitude (b) of ringing sites ( $\mathrm{n}=$ 33 in both cases).

the harsher winter climate in northern and eastern regions. Our results support the notion that the Water Rail is a facultative migrant (Flegg \& Glue 1973, Cramp \& Simmons 1980, De Kroon 1984, Taylor \& van Perlo 1998). The Water Rail probably needs access to open water for food during winter (Jenkins et al. 1995) and the most appropriate winter habitats are therefore most likely situated near the coast of Western Europe where winters are relatively mild. Due to the species' facultative migration habits and tendency to vary in numbers in relation to weather conditions (Jenkins et al. 1995, Lislevand \& Kjøstvedt 2005) climatic variation should be expected to affect migration in this species. To strengthen the foundation for future analyses of such ecological relationships and migration in general, we encourage an increased ringing effort on Water Rails in Europe, especially in the northern and eastern parts of the species' distribution area where few ring recoveries are currently available. Ringing activities should however not be reduced in other parts of the distribution area. More data are for example needed on how movements vary with sex and age in the species 
and extensive ringing might provide a possibility to carry out analyses on this issue in the future. Since migration behaviour is still generally poorly known in Water Rails, all studies on this aspect would be valuable even if they are carried out on restricted populations.

Acknowledgements. We thank EURING for supplying the data set analysed in this paper. We are also grateful to the late Torstein Solhøy for his encouraging suggestions on this study, and two anonymous reviewers for their constructive comments on a previous version of the manuscript.

\section{REFERENCES}

Alerstam, T. 1990. Bird migration. Cambridge University Press, Cambridge.

Baillie, S.R. 2001. The contribution of ringing to the conservation and management of bird populations: A review. Ardea 89: 167-184.

Bairlein, F. 2001. Results of bird ringing in the study of migration routes. Ardea 89: 7-19.

Bakken V., Runde, O. J. \& Tjørve, E. 2003. Norwegian Bird Ringing Atlas. Stavanger Museum, Stavanger. (In Norwegian with English summary)

Batschelet, E. 1981. Circular Statistics in Biology. Academic Press, New York.

Berthold, P. 2001. Bird migration: a general survey. Oxford University Press, Oxford.

Bowlin, M.S., Bisson, I.-A., Shamoun-Baranes, J., Reichard, J.D., Sapir, N., Marra, P.P., Kunz, K.K., Wilcove, D.S., Hedenström, A., Guglielmo, C.G., Åkesson, S., Ramenofsky, M. \& Wikelski, M. 2010. Grand challenges in migration biology. Integrative and Comparative Biology 50: 261-279.

Clark, J.A., Thorup, K. \& Stroud, D.A. 2009. Quantifying the movement patterns of birds from ring recoveries. Ringing \& Migration 24: 180-188.

Cramp, S. \& Simmons, K. 1980. Handbook of the Birds of Europe, the Middle East, and North Africa - The birds of Western Palearctic. Oxford Press, Oxford.

De Kroon, G.H.J. 1982. Kurze Mitteilungen - Überwintert die Wasserralle (Rallus aquaticus) in Mitteleuropa? Die Vogelwarte 31: 460-461.

De Kroon, G.H.J. 1984. Zug und Wintervorkommen der Wasserralle (Rallus aquaticus) in Europa. Beiträge zur Vogelkunde 30: 97-110.

du Feu, C.R., Clark, J.A., Schaub, M., Fiedler, W. \& Baillie, S.R. 2016. The EURING Data Bank - a critical tool for continental-scale studies of marked birds. Ringing \& Migration 31: 1-18.

Flegg, J.J. M. \& Glue, D.E. 1973. A Water Rail Study. Bird Study 20: 69-80.

Fransson, T., Ôsterblom, H. \& Hall-Karlsson, S. 2008. Svensk ringmärkningsatlas. Vol. 2. Stockholm.

Faaborg, J., Holmes, R.T., Anders, A.D., Bildstein, K.L.,
Dugger, K.M., Gauthreaux, S.A. Jr., Heglund, P., Hobson, K.A., Jahn, A.E., Johnson, D.H., Latta, S.C., Levey, D.J., Marra, P.P., Merkord, C.L., Nol, E., Rothstein, S.I., Sherry, T.W., Scott Sillett, T., Thompson III, F. R. \& Warnock, N. 2010. Conserving migratory land birds in the New World: do we know enough? Ecol. Appl. 20: 398-418.

Glutz von Blotzheim, U.N. 1973. Handbuch der Vögel Mitteleuropas. Frankfurt.

Imboden, C. \& Imboden, D. 1972. Formel für Orthodrome und Loxodrome bei der Berechnung von Richtung und Distanz zwischen Beringungs- und Wiederfundort. Vogelwarte. 26: 336-346.

Jenkins, R.K.B., Buckton, S.T. \& Ormerod, S.J. 1995. Local movements and population density of water rails Rallus aquaticus in a small inland reedbed. Bird Study 42: 82-87.

Lislevand, T., \& Kjøstvedt, J.H. 2005. Wintering Water Rails Rallus aquaticus in Aust-Agder county, South Norway. Ornis Norvegica 28: 118-125.

Lund, U. \& Agostinelli, C. 2007. circular: Circular Statistics. $\mathrm{R}$ package version $0.3-8$.

Mork, K. 1994. Litt om overvintrande vassrikser (Rallus aquaticus) i Noreg. Ringmerkaren 6: 210-211.

Newton, I. 2008. The migration ecology of birds. Elsevier, Amsterdam.

Norwegian Ring Recoveries Atlas 2017. http://must. ringmerking.no/kart.asp. Accessed 27th October 2017.

Perdeck, A.C. 1977. The analysis of ringing data: pitfalls and prospects. Vogelwarte 29: 33-44.

R Development Core Team 2013. R: A language and environment for statistical computing. $\mathrm{R}$ Foundation for Statistical Computing, Vienna, Austria. ISBN 3-900051-07-0. http://www.R-project.org.

Saurola, P., Valkama, J. \& Velmala, W. 2013. The Finnish Bird Ringiung Atlas. Vol. I. Finnish Museum of Natural History and Ministry of Environment, Helsinki.

Taylor, B. \& van Perlo, B. 1998. Rails: a guide to the rails, crakes, gallinules and coots of the world. Pica Press, London.

Taylor, B. 1996. Family Rallidae (Rails, Gallinules and Coots). Pp. 108-210 in: del Hoyo, J., Elliott, A. \& Sargatal, J. (eds.). Handbook of the Birds of the World. Vol. 3. Hoatzin to Auks. Lynx Edicions, Barcelona.

Terrill, S.B. \& Able, K.P. 1988. Bird migration terminology. Auk 105: 205-206.

Thorup, K., \& Conn, P.B. 2009. Estimating the seasonal distribution of migrant bird species: can standard ringing data be used? Pp. 1107-1117 in: Thomson, D., Cooch, E. G. \& Conroy, M. J. (eds.). Modeling Demographic Processes in Marked Populations. Environmental and Ecological Statistics, Vol. 3. Springer, Boston, MA.

Received 29 January 2018. Accepted 19 October 2018 